

\title{
TERRITORIALIDADES EM REDES DIGITAIS DE CULTURAS GLOBAIS: JUVENTUDES DE FAVELAS E PERIFERIAS EM SUAS ESTÉTICAS DE ATITUDE
}

\author{
Jorge Luiz Barbosa \\ Universidade Federal Fluminense - Brasil \\ jorge_barbosa@id.uff.br
}

Territorialidades em redes digitais de culturas globais: juventudes de favelas e periferias em suas estéticas de atitude (Resumo)

As relações entre o mercado, o consumo e a cultura assumiram dimensões inimagináveis na definição do sentido das cidades contemporâneas. A expansão das tecnologias de informação e comunicação contribuiu decisivamente para tais condições, uma vez que se trata da ampliação da circulação de imagens visuais e sonoras em redes digitais. É nesse novo campo de relações que conflitos, insurgências e enfrentamentos emergem com maior ou menor vigor, caracterizando as tensões da cultura globalizada com as vivências locais, provocando questionamentos sobre a força homogeneizadora das dos dispositivos digitais no cotidiano dos mais diversos grupos sociais. É justamente neste complexo cenário que surgem autorias outras para marcar suas estéticas de atitude em territorialidades de pertença. São os jovens e as jovens de subúrbios, periferias e favelas a desafiar os processos globalizados de consumo de identidades, símbolos e valores com suas práticas de invenção e compartilhamento de experiências culturais.

Palavras chave: território, territorialidade, juventudes, cultura globalizada

Territorialities in digital networks of global cultures: youth from slums and peripheries in their attitude aesthetics (Abstract)

The relations between market, consumption, and culture are instrumental to define the sense of contemporary cities. Information and communications technologies have a decisive for circulation of visual and audio images. Conflicts, insurgencies and clashes emerge with higher or lower vigor, characterizing tensions of a globalized culture, therefore raising questions about the homogenous power of digital medias. It is in this complex scenario that new authorships emerge, marking their aesthetic of attitude. Those are young people from peripheries and slums that defy globalized consumption processes of identities, symbols and values with their practices of invention and sharing of cultural experiences.

Keywords: territory, territoriality youths, globalized culture 


\section{Primeiras argumentações}

O território é produto das condições de nossas experiências de vida, bem como dos investimentos imagéticos com os quais simbolizamos a nossa experimentação corpórea do mundo. Podemos afirmar, então, que a cultura e o território possuem relações mais do que próximas, uma vez que se realizam em intricadas relações tangíveis e intangíveis, sobretudo se consideramos a cultura com um campo de invenções materiais e simbólicas compartilhadas entre indivíduos e coletivos sociais. Entretanto, quando vivemos em relações globalizadas pelo mercado de produção e consumo cultural, começamos a indagar qual é o papel dos sujeitos sociais em seus territórios de existência nas condições de desigualdade que se fazem hegemônicas no contemporâneo ${ }^{1}$.

Na linha anunciada, o presente artigo busca colocar em causa as contradições inerentes aos processos de globalização que friccionam modos de fazer, organizar e experimentar a produção e a fruição cultural em nossas cidades. Trata-se, portanto, de provocar o debate sobre a cultura nas tensões provocadas pela apropriação e uso de redes técnicas de informação e comunicação digital e suas implicações na configuração de sentidos da cidade no contemporâneo, particularmente no que concerne às práticas de juventudes de territórios populares.

Será privilegiada em nossa análise a relação dos sujeitos criadores em seus territórios de existências diante do mercado fundado em processos globalizados de produção e circulação de identidades, ícones e valores culturais e estéticos hegemônicos, tendo como sua referência as vivências socioculturais de jovens da cidade do Rio de Janeiro (Brasil). Nossa perspectiva é sublinhar movimentos em territorialidades virtuais e presenciais como modos de afirmação de direitos de ser visto e ser ouvido por parte de juventudes invisibilizadas em nossas metrópoles desiguais.

\section{O território no contexto técnico-científico contemporâneo}

No atual contexto técnico-científico, os meios e os objetos passaram a ser ao mesmo tempo técnicos e informacionais, devido à extrema intencionalidade de sua produção social e de sua localização geográfica ${ }^{2}$. A energia principal do funcionamento destes meios e objetos seria a informação, tornando seu controle e sua difusão um novo modo de poder sociopolítico em distribuição desigual no mundo globalizado.

É nesta perspectiva que a ciência, a tecnologia e o meio técnico passam a coordenar decisivamente os processos de produção, circulação e comunicação socioespacial, trazendo no seu bojo relações cada vez mais complexas de produção, recepção e consumo de bens e serviços materiais e simbólicos ${ }^{3}$.

\footnotetext{
1 A expressão globalização surgiu como discurso retórico e, ao mesmo tempo, como dispositivo analítico mobilizado para descrever mudanças na organização social, econômica e política do mundo contemporâneo. E como assinalam Featherstone, Lash e Robertson (1995), acabou por contaminar também o domínio cultural, originado expressões como cultura global; cultura globalizada; globalização da cultura etc.

${ }^{2}$ Santos, 2002.

${ }^{3}$ Para Castells (2003), a emergência das tecnologias de informação e comunicação é caracterizada pelo seu alcance global, pela integração de todos os meios de comunicação e pela interatividade que está mudando para sempre a nossa cultura.
} 
No que concerne ao presente artigo, estamos interessados em colocar em causa o que vem sendo definido como globalização cultural, largamente originada das formas massificadas de produção e consumo de bens simbólicos e que se realiza rasgando fronteiras de modos culturais mais ou menos estabelecidos entre as sociedades.

A característica principal deste processo global seria a "compressão espaço/tempo" - definida por D. Harvey (2005) como a redução de barreiras espaciais por meio da aceleração do tempo - responsável pelo encurtamento das distâncias físicas e, com isso, fazendo com que eventos delimitados em geografias próprias provoquem impactos imediatos sobre pessoas e territórios situados em distintas latitudes. Todavia, suas implicações são diversas e, sem dúvida, afetam o nosso cotidiano de modo desigual e combinado. Então, devemos estar criticamente atentos às relações de hegemonia que se fazem presentes com a redução das distâncias físicas pela velocidade dos fluxos informacionais. De modo mais específico devemos estar atentos aos centros de produção e difusão de bens simbólicos como uma construção homogeneizadora de imaginários:

Os conglomerados que objetivam o domínio do mercado da fabricação de símbolos culturais universais usam, a seu modo, o mundo ilimitado da tecnologia de informação (...). Os satélites permitem ultrapassar todas as fronteiras nacionais e de classe e plantar um brilhante mundo - cuidadosamente inventado - da América branca aos corações das pessoas em todos os cantos do mundo ${ }^{4}$.

Tornar-se incrivelmente avassaladora a circulação de imagens visuais e sonoras mobilizadas e expandidas em ambientes digitais corporativos (televisão por assinatura, facebook, sites, telefonia celular), constituindo o mercado cultural em extensão global. Fronteiras culturais mais ou menos rígidas são atravessadas, fragilizadas e, até mesmo, diluídas diante da massificação da produção e consumo de signos efêmeros.

O consumo de bens simbólicos na era da reprodutibilidade técnica da cultura globalizada 5 desigualmente distribuído entre classes, grupos e indivíduos, traduz comportamentos solváveis e modulados como referência do sucesso e gozo individual. Há, portanto, um modo de reprodução de posições sociais hierarquizadas intimamente vinculada ao consumo distintivo de bens e serviços simbólicos.

A cultura passa a assumir, nas condições em descrição, um papel de centralidade na produção e circulação das mercadorias, tornando-se uma das comodities mais valorizadas das economias financeiras e industriais dos espaços centrais do capitalismo. Gile Lipovetsky e Jean Serroy (2015) afirmam que a globalização das mercadorias culturais significou uma espécie de estetização do mundo; um embelezamento dos objetos segundo modelagens conversíveis e flexíveis de bens e serviços, presididas pelo consumo do efêmero e do espetacular:

Todos os dias o mundo industrial se cruza um pouco mais com o universo da moda. Depois do automóvel, os utensílios de cozinha e de banheiro, as escovas de dentes, a lingerie, os

\footnotetext{
4 Berck, 1998, p. 82.

${ }^{5}$ Essa expressão é tomada de empréstimo do artigo A Obra de Arte na Era da Reprodutibilidade Técnica. Benjamin, 1994.
} 
calçados esportivos, os óculos, os relógios não são mais apenas produtos "técnicos", mas artigos de grife, incessantemente renovados e apresentados em coleções (... $)^{6}$.

Estamos diante de um sistema de trocas intersubjetivas que regulam a produção e consumo de bens e serviços saboreados como se fossem sensações (prazer, sucesso, vitória, superioridade). Acabamos mergulhados em uma economia do gozo que estetiza o consumo de objetos e limita o corpo e o território à esfera do espetáculo. Desse modo, as práticas sociais passam a ser mediadas por um sistema técnico-imagético unidirecional, cujo objetivo é alcançar os mais distintos recantos do mundo para impor a sua economia de poder simbólico, uma vez que a forma mais eficaz de globalização se dá pela colonização do imaginário: condição que faz da cultura uma das importantes centralidades da política no contemporâneo, inclusive de modelagens urbanas seletivas nas cidades ${ }^{7}$.

Os territórios da vida social são também impactados pelos sistemas de informação, comunicação e mobilidade espaciais, compreendendo mudanças dos costumes e valores locais quando friccionados com os elementos globais, uma vez que estamos diante de modos comunicativos que criam novas formas de percepção e compreensão do mundo. Para Milton Santos (2002), a globalização que chegou às classes populares veio carregada de uma cultura mercadológica que coloca o dinheiro como centro das relações humanas e as relações humanas como "mercadoria indiferente às heranças e às realidades atuais dos territórios e das sociedades" $"$.

Tais relações identificadas são construções verticalizadas que aportam nos territórios em um movimento de reprodução da hegemonia econômica e ideológica de empresas corporativas e, em seu curso de realização geográfica, promovem o aprofundamento de contradições entre o local e global ${ }^{9}$. Entretanto, as forças das verticalidades defrontadas com usos do cotidiano do território conduzem o agravamento de conflitos oriundos das imposições e dos interesses dos processos de racionalização instrumental sobre usos, recursos e populações do território em um processo de alienação material e subjetiva.

A questão proposta ao debate é a relação cada vez mais entrelaçada entre o mercado, o consumo e a cultura na construção de posições e distinções simbólicas no âmbito da reprodução social e das relações de poder que as estruturam. Afinal, o que é consumido confere ao consumidor o poder de se diferenciar do outro, ostentar posições de reconhecimento social e afirmar vínculos sociais hierárquicos. Trata-se, portanto, de um regime de classificações de sujeitos e territórios na ordem social contemporânea, cujas mediações são dadas pelo consumo privilegiado, especialmente de bens e serviços simbólicos, e não pelos direitos à cidadania. Todavia, é possível reconhecer conflitos, insurgências e enfrentamentos ao processo de globalização da cultura, ou melhor, do domínio mercantil da cultura globalizada:

\footnotetext{
${ }^{6}$ Lipovetsky e Serroy 2015, p. 80.

7 Explica-se a atual preferência pelas requalificações ou revitalizações urbanas com a implantação de equipamentos grandiosos (museus, galerias, centro culturais, aquários, galerias de arte) para criar novas imagens de cidade como ambiência atraente de consumo e distinção social. (Boston, Roterdã, Barcelona, Bilbao, Londres, Cidade do Cabo, Buenos Aires e Rio de Janeiro, são exemplos característicos da modelagem urbana em curso). ${ }^{8}$ Santos, 2002, p. 143.

${ }^{9}$ Quem produz, quem comanda, quem disciplina, quem normaliza, quem impõe uma racionalidade às redes em mundialização? Esse mundo em rede é o do mercado universal e dos governos mundiais: O Fundo Monetário Internacional, o Banco Mundial, o GATT, as organizações internacionais, as Universidades mundiais (Santos, 2003).
} 
Com a globalização, a política cultural passa a se inscrever num conjunto mais amplo de demandas e formas de luta e pertença simbólica que veiculam pretensões de reconhecimento de culturas, étnico, sexual, afetivo e de potencialidades criativas inscritas em redes locais específicas de organização coletiva e individual ${ }^{10}$.

No atual contexto sociopolítico em que as tecnologias de informação e comunicação jogam papéis decisivos no processo de produção e de circulação, os mais conectados em redes técnicas alcançam maior poder de decisão e inserção na ordem social contemporânea. Todavia, como considera Milton Santos, as "minorias" também podem se apropriar dos meios técnicos e de tecnologias utilizadas em benefício da cultura de massa e da cultura hegemônica para promover a revanche da cultura popular "os pobres abrem um debate novo, às vezes silencioso, às vezes ruidoso, com as populações e coisas já presentes, encontrando novos usos e finalidades para objetos e técnicas e também novas articulações e novas normas de vida social" $"$.

De fato, os meios de produção, circulação e consumo simbólico têm se expandido consideravelmente a partir da difusão de tecnologias de informação e comunicação, provocando novas condições de recepção, percepção e experimentação cultural que anulam distâncias de métricas físicas. Encontros de tensões, braconagens e colagens culturais passaram a fazer parte de nosso cotidiano de modo intenso e plural, tornando permeáveis, cambiáveis, e não menos conflitivas, as condições de produção e comunicação da cultura ${ }^{12}$.

É sob a égide destas novas condições gerais e específicas de manifestação da existência social que as narrativas estéticas populares conseguem romper clausuras e provocam fissuras, mobilizando sujeitos e atos de afirmação da diferença sociocultural. A força dessa transposição de barreiras e limites espaço-temporais vem sendo um exercício de jovens que mobilizam e são mobilizados por meio do uso de tecnologias de comunicação, especialmente por parte das juventudes de grupos populares urbanos mesmo em condições de profunda desigualdade em relação a outros grupos e classes sociais ${ }^{13}$.

\section{Identidades e territórios em disputa nas culturas globalizadas}

Como observa Massimo Canevacci, as identidades culturais exploram cada vez mais diversos discursos, estilos, visões, percepções e criações em múltiplas experimentações que não cessam de ser inventadas e cobiçadas durante a sua vida ${ }^{14}$. Não há muitas dúvidas do papel jogado pelos meios de comunicação e informação na mobilização e na circulação de signos e símbolos na diversidade do mundo, o que levou a Pierre Lévy (1999) a considerar a emergência de ciberculturas como resultantes da mutação da própria essência da cultura. Contraditoriamente, como afirma Stuart Hall, a nova experiência social se realiza como um 'supermercado cultural', sobretudo devido ao consumismo global permeado por estilos, lugares e imagens - onde as

\footnotetext{
${ }^{10}$ Tereza Ventura 2010, p. 119.

${ }^{11}$ Santos, 2002, p. 326.

12 Costa e Barbosa, 2016.

${ }^{13}$ Dados da pesquisa Tic Kids Online Brasil, desenvolvida pelo CETIC.br (Centro Regional de Estudos para o Desenvolvimento da Sociedade da Informação) nos revelam que cerca de oito em cada dez crianças e adolescentes com idades entre 9 e 17 anos eram usuários de Internet em 2016, correspondendo a 24,3 milhões de usuários milhões de usuários no Brasil. Ver <www.cetic.br/media/analises/tic_kids_online_brasil_2017>.

142005 , p. 91.
} 
identidades se desvinculam de tempos, espaços, histórias e tradições específicas - flutuando livremente e seduzidas por diversas e distintas referências simbólicas ${ }^{15}$.

Apesar de nossa concordância com a leitura de Hall (2006), acreditamos que os modos de pensar e agir ainda estão em disputa no contexto da globalização colonizadora de imaginários. O domínio de tecnologias de produção e difusão para mobilizar novas experiências territoriais se tornou fundamental e, no seu desdobramento de realização de ações, faz emergir a construção de territorialidades ${ }^{16}$ de diferentes manifestações de existências, inclusive sendo impulsionada com a expansão do uso da internet ${ }^{17}$. É possível identificar a emergência de marcações de pertencimentos em outros repertórios contrapontísticos ao regime hegemônico de produção e consumo de bens e serviços simbólicos massificados. Portanto, movimentos inovadores de construção de visibilidades corpóreas de direitos estão em curso. É nesse sentido mais específico que as mídias industriais se tornam uma arena de disputas de imaginários no contemporâneo:

A mídia, portanto, constituir-se-ia em um dos principais cenários do debate contemporâneo; é através dela, de modo geral, que se adquire visibilidade e que se constroem os sentidos de grande parte das práticas culturais. (...) Por outro lado, é também nos meios de comunicação de massa que se desenvolvem grande parte dos processos de estigmatização ou mesmo criminalização das culturas minoritárias, na medida em que acontecimentos, fatos, rituais e, de forma geral, a "realidade social" ali ganha sentido e se multiplicam com a difusão do uso da internet no país ${ }^{18}$.

Para a nova composição de papel das mídias industriais de massa é por demais decisivo a apropriação e o uso de tecnologias de produção e difusão, sobretudo como suporte de invenção de meios criativos e modos de comunicação de suas narrativas em diferentes linguagens artísticas e culturais (música, dança, cinema, grafitti, fotografia, literatura, audiovisual), combinando corpo, técnica e território na sua afirmação individual e coletiva na sociedade. É verdade que as tecnologias digitais associadas às mídias industriais provocam a desestabilização das relações que envolviam a identidade, a cultura e o território. Todavia, é preciso também assinalar as possibilidades da reconstrução dos laços em virtualidades e virtudes diferenciadas para construir pertencimentos entre territórios e culturas, fazendo emergir potências e atos de afirmação de relações de pertença com territórios de vivências socioculturais.

É assim que mídias virtuais e práticas territorializadas passam a envolver experiências sensíveis que abrigam e exteriorizam existências individuais e coletivas corporificadas. São, portanto, investimentos simbólicos, éticos e estéticos que promovem a visibilidade de sujeitos nas tensões de imaginários sobre o significado de viver em sociedade. É justamente tendo esta cena em perspectiva que situamos as práticas culturais urbanas como o funk, o hip hop, o slam, o pixo e

\footnotetext{
15 2006, p. 75.

${ }^{16} \mathrm{O}$ conceito de territorialidade encontra sua inspiração particular no capitulo The meaning of territoriality do livro Human Territoriality: its theory and history de Robert David Sack (1986). Neste artigo pioneiro, a territorialidade é tratada como uma estratégia de poder social em escalas espaciais da vida cotidiana às organizações complexas, cujo propósito tangível é afetar as relações presentes na sociedade.

${ }^{17}$ Segundo o IBGE, 70,5\% dos lares brasileiros passaram a contar com acesso à internet em 2017, isso significou 49,2 milhões de domicílios conectados em 2019. Esse número representa um crescimento significativo em relação aos 44 milhões $(63,6 \%)$ registrados em 2016, ainda mais se incluirmos na conta que até 2013 menos da metade das residências tinha algum tipo de acesso à internet no país. Pesquisa Nacional por Amostra de Domicílios Contínua (Pnad Contínua), 2017.

${ }^{18}$ Herschmann, 2005, p. 90.
} 
o grafitti - elaboradas em territórios populares, porém inscritas no espaço urbano na interseção de cultura, arte e tecnologia - como sociabilidades que renovam experiências de encontros e afirmam a pluralidade estética da sociedade, assim como interpelam com vigor as condições de democracia e de cidadania em seus territórios de existências sociais.

Não devemos acolher com surpresa que jovens de favelas e periferias urbanas inventem, por si mesmos, suas imagens (sonoras, visuais, tácteis) corporificadas e, com elas, possam mover os desafios sociopolíticos face ao regime distintivo de classificação da vida na sociedade. Em pesquisa realizada pelo Observatório de Favelas com dois mil jovens residentes em cinco grandes favelas da cidade do Rio de Janeiro, observou-se que grande parte dos entrevistados inventava seus acessos às redes digitais por meio de celulares ${ }^{19}$, superando a limitada oportunidade de possuir um computador em suas residências e escolas e, com esse acesso, mobilizar formas de comunicação e processos de criatividade estética:

Quadro 1. Uso do Celular por Favela dos Entrevistados (\%)

\begin{tabular}{|c|c|c|c|c|c|}
\hline $\begin{array}{c}\text { Uso do } \\
\text { Celular }\end{array}$ & $\begin{array}{c}\text { Complexo do } \\
\text { Alemão }\end{array}$ & $\begin{array}{c}\text { Cidade de } \\
\text { Deus }\end{array}$ & Rocinha & Manguinhos & $\begin{array}{c}\text { Complexo da } \\
\text { Penha }\end{array}$ \\
\hline Fotografar & 47,3 & 61,8 & 66 & 51 & 72 \\
\hline $\begin{array}{c}\text { Produzir } \\
\text { vídeos }\end{array}$ & 37,6 & 43 & 48 & 46 & 55 \\
\hline $\begin{array}{c}\text { Trocar } \\
\text { Arquivos }\end{array}$ & 48,2 & 60 & 58 & 62 & 73 \\
\hline
\end{tabular}

Fonte: Solos Culturais <https://pt.scribd.com/document/207566999/Solos-Culturais>.

Como podemos perceber, os jovens de favelas não são consumidores passivos de bens simbólicos que circulam sem cessar nas redes sociais. A composição e a difusão de músicas, vídeos, fotografias por parte das juventudes das favelas são narrativas de si e de seus territórios, e ganham mobilizações muitas vezes inesperadas nas mídias virtuais, fazendo a superação de fronteiras outrora mais rígidas e limitadoras impostas pelos poderes discricionários de meios industrias hegemônicos de informação para o reconhecimento entre si (e para si) de jovens marcados com estigmas de violência e estereótipos de carência. A inflexão do emprego do celular como objeto de consumo para dispositivo de criação, registro e comunicação de imagens (sonoras e visuais) opera uma mudança radical da posição de jovens de territórios populares na circulação das culturas no/do espaço urbano.

De meros representados por outros distantes, os jovens de favelas se apresentam para criar uma escrita de si com outros, traduzindo relações de afirmação de sua presença na cidade e da existência de seus territórios de morada.

A exibição e publicação em redes digitais possibilita interações que conectam diferentes sujeitos e suas distintas espacialidades em torno referenciais estéticos comuns. A participação nas mídias sociais, além de possibilitar visibilidade, informa as urgências do presente e potencializa a mobilização para encontros e celebrações presenciais.

\footnotetext{
${ }^{19}$ No Brasil, segundo pesquisa realizada pelo Instituto Brasileiro Geografia e Estatística em 2017, houve uma imensa expansão do acesso à internet via celular, alacando $92 \%$ dos domicílios no Brasil. Ver <https://tecnologia.ig.com.br/2018-04-27/acesso-a-internet.html>
} 


\section{Territorialidades de estéticas de atitude}

Para Milton Santos "a cultura e territorialidade são, de certo modo, sinônimas"20, uma vez que a cultura é um processo imerso na vida simbólica e material dos grupos sociais. Assim como a territorialidade é um produto de relações estabelecidas a partir do movimento de demarcação/ocupação/posse simbólica do território. Sendo assim, é possível identificar territorialidades nas práticas discursivas, gestuais e performáticas dos sujeitos sociais marcadas em praças, esquinas e viadutos.

É nesse sentido que muitas experiências e experimentações de territorialidades atuam na afirmação de pertenças plurais ao promover a circulação de narrativas e desenhar um novo campo de afirmação cidadã e, ao seu modo, retomam para si a construção do virtual como territorialidade de realização de suas potências socioculturais.

A mobilização em redes digitais vem contribuindo decisivamente com o aludido processo, uma vez que desvincula atos de circunstâncias espaço-temporais imediatas e permite alcance de outros muitos em contextos culturais diversos. Páginas de facebook, blogs, fotologs, crews de graffiti, páginas digitais e sites são dispositivos de mediação entre autores coletivos e individuais e contribuem para que estes se desprendam de suas localizações fixas, construindo assim os movimentos e os circuitos mais amplos de interações comunicativas de repertórios artísticos e culturais. Todavia, as especificidades culturais presentes no território passam a ressaltar os atributos diferenciais deste mesmo território e como mobilização de um ativo simbólico territorial na relação entre sujeitos e, evidentemente, com outros sujeitos individuais e coletivos de outros territórios inscritos na ordem urbana dominante.

Dos ambientes virtuais são também mobilizadas territorialidades corporificadas pelos atores conectados em rede, agora traduzidos em encontros presenciais. São, na verdade, um movimento de dobras constitutivas de ações que compreendem configurações em praças, ruas, esquinas, viadutos, estações rodoviárias e estacionamentos de shopping centers. Mesmo que efêmeras, ou mais duradouras, tais cenas culturais são organizadas e movimentadas com o apoio de tecnologias de informação e comunicação, tornando-se estratégias fundamentais de aparição simbólica e corpórea de jovens de favelas, subúrbios e periferias na reconfiguração de seus modos de visibilidade.

\footnotetext{
${ }^{20} 2002$, p. 61.
} 


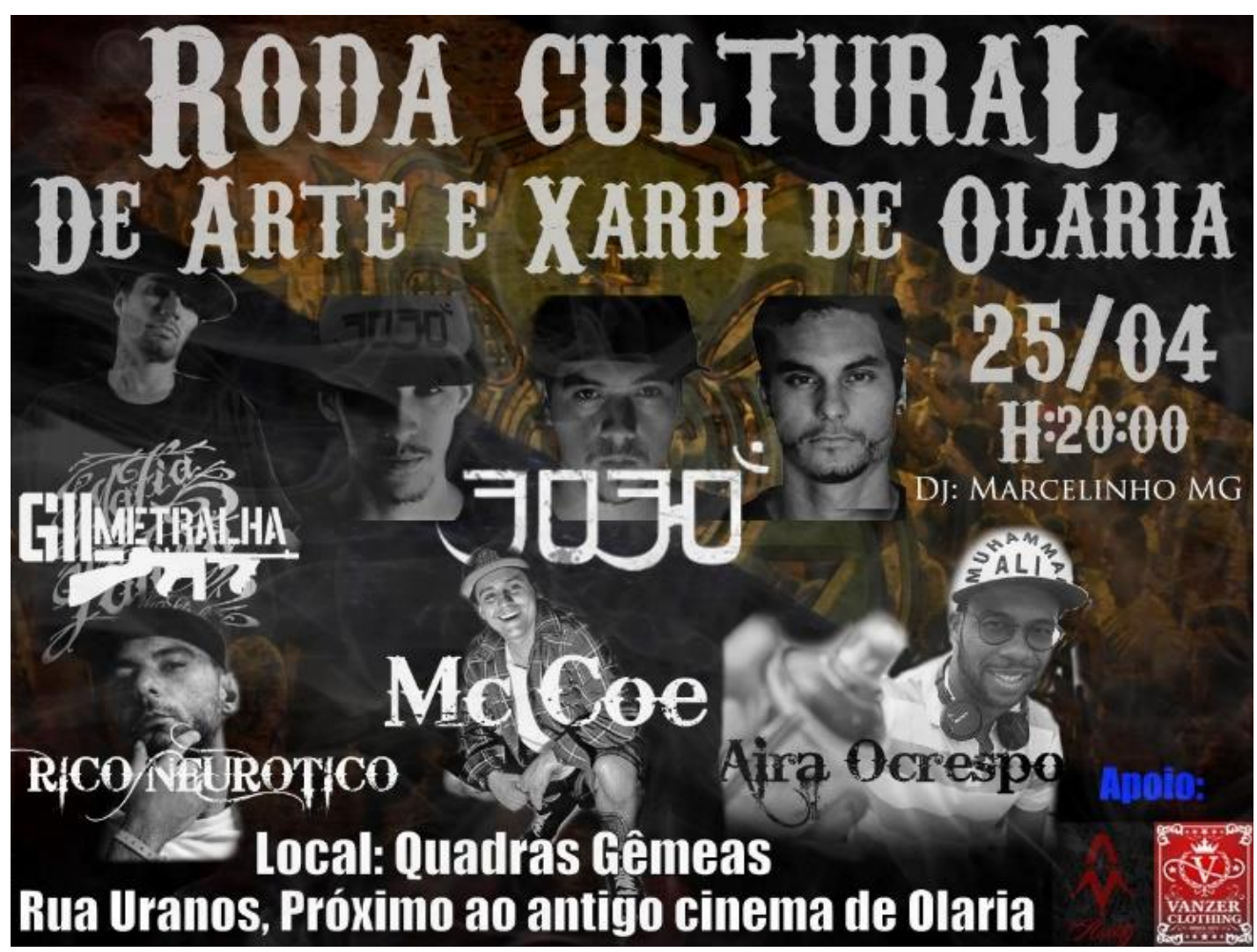

Fonte: <https://pt-br.facebook.com/RodaCulturalDeOlaria>

Como os próprios autores expressam em sua descrição no Facebook: "A Roda Cultural de Olaria é um evento cultural gratuito e independente, organizado por jovens ativistas culturais do bairro do subúrbio da cidade do Rio de Janeiro". Promover a valorização do espaço público, juntar diferentes grupos e repertórios estéticos, assim como mobilizar aqueles que moram no bairro, ou em suas proximidades, para celebrações de suas estéticas, são os destaques principais para as convocações em mídias digitais. As Rodas Culturais operam a transcodificam de territorialidades virtuais em territorialidades corporificadas, fazendo emergir ocupações de visibilidade de jovens nas ruas, praças e viadutos de nossas metrópoles. Destacamos que tais mediações virtuais contribuíram para a formação da Liga de Rodas Culturais do Rio de Janeiro, hoje contando com 250 rodas de rima como filiadas.

As narrativas estéticas inventadas em territórios específicos reverberam em fluxos de experiências compartilhados entre jovens, geralmente acantonados em territórios urbanos em condições extremas de desigualdades. Os jovens traçam e fazem encontros presenciais ao fazer uso de escalas fundamentais do contemporâneo: a virtual e a corpórea. As apropriações possíveis de tecnologias de comunicação passam a funcionar como mediações de afetos e pertenças entre jovens desapropriados das condições de auto-apresentação ${ }^{21}$. Tornam-se sujeitos situados em territórios simbólico-existenciais que mobilizam e manejam meios de

\footnotetext{
${ }^{21} \mathrm{Na}$ cidade do Rio de Janeiro estavam ativas, até 2018, 250 rodas culturais, sobretudo em praças e bairros dos subúrbios e periferias cariocas. Destacam-se também os cineclubes, os saraus e os slams, como esses encontros de experiências estéticas mobilizados pelas juventudes em redes virtuais. Ver <http://www.culturasdeperiferia.org.br/>.
} 
produção e comunicação desafiadores das condições discricionárias de espaço/tempo e, a seu modo, demandam sua inserção no movimento de urbanidade configurada pelos meios tecnológicos ${ }^{22}$.

Esse ativismo em redes digitais complexas conforma coletivos políticos na cena urbana em seu sentido plural, uma vez que não se trata de movimentos identitários em causa única, mas sim da multiplicidade de desejos encarnados em práticas de pertença sociocultural, fortemente expressas em suas músicas, poesias, danças e pinturas, sobretudo em estilos retraduzidos de culturas urbanas globais como funk e hip hop.

O processo em causa é criador de territorialidades, aqui definida como marcações móveis que se estabelecem como assinaturas autorais, com estilos de produção e perfomances de mobilização de subjetividades de sujeitos situados. São as posições geográficas de encontros que fazem a diferença sociocultural emergir como potência de mudança e disposição contrapontística aos regimes de hierarquização social.

Trata-se, portanto, de uma redescoberta do sentimento de pertencimento ao território colocando em questão a alienação cultural ou marginalização pelo consumo impulsionado pela globalização. É desse movimento que emergem novas construções identitárias de (re)encontros com tradições culturais e de (re)traduções estéticas contemporâneas. É por essa via que galeras vinculadas às rodas culturais de hip-hop, do slam e dos bailes funks reverberam seus repertórios para além de sua geografia local, apresentando suas performances estéticas para além das vivências territorializadas em suas comunidades de morada. Um exemplo qualificado são as rodas de rima que reúnem mestres de cerimônia, rappers e grafiteiros em praças, esquinas e viadutos em nossas metrópoles agigantadas como Rio de Janeiro, São Paulo, Belo Horizonte, Fortaleza, Salvador, Recife e tantas outras cidades brasileiras. Todas essas rodas estabelecem vínculos e difundem a mobilização por meio do uso de tecnologias digitais para encontros presenciais na cidade.

Os meios e as técnicas de comunicação são também incorporados à produção estética dos territórios populares. É assim que os repertórios criados nas favelas e periferias ganham reverberação em programas de TV e de rádio para ganhar escalas geográficas mais amplas de difusão. Isto tem tudo a ver com a produção musical, com as centenas de filmes disparados pela internet e com os bailes que mobilizam diferentes jovens de diferentes bairros das cidades. Há uma cultura de massas em ascensão nas favelas e nas periferias que, inclusive, transborda fronteiras para anunciar alegrias, recusas, paixões e protestos no conjunto da cidade. Essas anunciações são, na sua complexa composição, estéticas de atitude que se revelam como referências fundamentais para as disputas de imaginário sobre o sentido da cultura e da própria cidade na qual vivemos.

Isto não significa concluir que os laços de identidade não se manifestam nas convivências socioculturais em territórios de pertença. Ou afirmar que as relações entre sujeitos e seus territórios se esfumam ou se liquidificam no nomadismo errante de signos autorreferentes do ciberespaço $^{23}$. Embora os significados dos laços entre sujeitos e territórios não sejam mais marcados pela unicidade de concepções e de práticas socializadas, as relações de enlace são

\footnotetext{
${ }^{22}$ A urbanidade é condição e meio atual de generalização da sociedade urbana, sobretudo ao estabelecer a extensão geográfica de valores, práticas, expectativas e perspectivas a partir de referências da vida urbana. Isto implica conceber o espaço urbano contemporâneo como uma experiência comunicacional, para além de seus atributos e conteúdos de forma e função objetivas e materiais.

${ }^{23}$ Costa e Barbosa, 2016.
} 
construídas e se renovam com a multiplicidade de trocas simbólicas realizadas em territorialidades cada vez mais diferenciadas e inusitadas. Rolés, rolézinhos, bailes, rodas e saraus, entre tantas outras expressões das culturas juvenis, demonstram os enlaces do virtual e do territorial nas cidades contemporâneas.

Os ambientes virtuais passam também a ser reconfigurados a partir de expressões de territorialidades corporificadas, tornando-os espaços de coexistências para multiplicação de narrativas sensíveis, e não exclusivamente para aceleração do consumo de sensações e banalização de individualismos.

Estamos diante de tensões de recodificação de autores e reconfiguração de conteúdos nas mídias virtuais, fazendo destas um campo de disputas de imaginários. É nesse movimento que os usos do You Tube, Facebook, Instagram, WhatsApp e Sítios de podcasting ganham contraditoriamente a condição de dispositivo de visibilidade para jovens de territórios populares. E, como sabemos, se trata da visibilidade de corpos em marcações de desejo e de demandas de existências sociais até então ocultadas na sociedade brasileira, principalmente de juventudes negras.

É nesta perspectiva que jovens negros se reúnem para criar e gerenciar a AFROFLIX <www.afroflix.com.br>, plataforma de streaming gratuita e colaborativa que exibe produções audiovisuais que priorizam negros e negras como figuras centrais dos enredos e valorizam personagens africanos e afro-brasileiros. Ou mesmo os sites como os Favelados no Mundo <https://www.youtube.com/channel> e o Diáspora Black <https://diaspora.black/> que afirmam de modo exemplar a marcação presença negra em nossas cidades e metrópoles como sujeitos de direitos.

Ingressar em cenas digitais significa apropriação e uso de tecnologias para afirmar a visibilidade do jovem de origem popular, geralmente estigmatizado como violento e desconhecido como cidadão. Esse processo significa, por outro lado, uma possibilidade formidável de ampliação de sua experiência de tempo/espaço, uma vez que sua mobilidade urbana é reduzida e constrangida por condições econômicas, sociais, raciais e territoriais. Entrar na comunicação digital foi um passo decisivo para sair da situação de viver no gueto e buscar outras experiências mais alargadas de cultura e sociabilidade.

Nas ruas os jovens e as jovens das favelas e periferias não são reconhecido(a)s como pessoas plenas. Não possuem sua cidadania reconhecida, seus corpos não estão abrigados e suas vidas são radicalmente desrespeitadas. Agora na sua "cena digital" eles se mostram, falam de si, identificam suas preferências, afirmam seus gostos, mostram seus desejos. Tudo isso porque estão com outros jovens e outras jovens em fluxos de desejos. paixões e demandas socioculturais.

Ao entrar em contato com jovens parecidos com eles e diferentes deles, compartilham diversos produtos simbólicos em redes digitais. Músicas, vídeos, fotos começam a circular para as apresentações de si e de seus territórios de morada. Há, portanto, a criação de pertenças. Pertenças que não são apenas virtuais, pois eles se comunicam com signos e significados que lhes são comuns, tendo com sua referência na rede de conversações o próprio vivido no território habitado por eles. 
As novas práticas, atitudes, modos de pensar e valores que se desenvolvem nesse contexto informacional transcendem, em muito, sua infraestrutura tecnológica material, para mobilizar novas experiências territoriais e, no seu desdobramento de realização, a construção de territorialidades de diferentes manifestações de existências de sujeitos sociais. Emergem assim marcações de pertencimentos para proclamar outras existências e outros territórios contrapontísticos ao regime hegemônico de representações globalizadas ${ }^{24}$.

Podemos falar, sem muitas dúvidas, da fragmentação, da seletividade e da hierarquização presentes na comunicação virtual ${ }^{25}$. Contudo, é possível também apostar nas possibilidades de aproximações entre distantes e para criação de convivências entre diferentes. É assim que os encontros acontecem provocados por dispositivos digitais. São chamados para experiências estéticas, para o compartilhamento de vivências simbólico-existenciais na cidade. É assim que jovens de diferentes favelas, loteamentos, conjuntos habitacionais e bairros da cidade do Rio de Janeiro são mobilizados e se mobilizam para celebrar suas estéticas de atitude em praças, avenidas, estacionamentos e viadutos para além dos seus territórios de morada. Indivíduos e coletivos passam a exercer sua mobilidade em uma intricada rede de apropriações da cidade e de criação de visibilidade para ressignificações de discursos e de práticas socioespaciais insurgentes.

Figura 2. Cena de Slam na favela do Alemão (cidade do Rio de Janeiro)

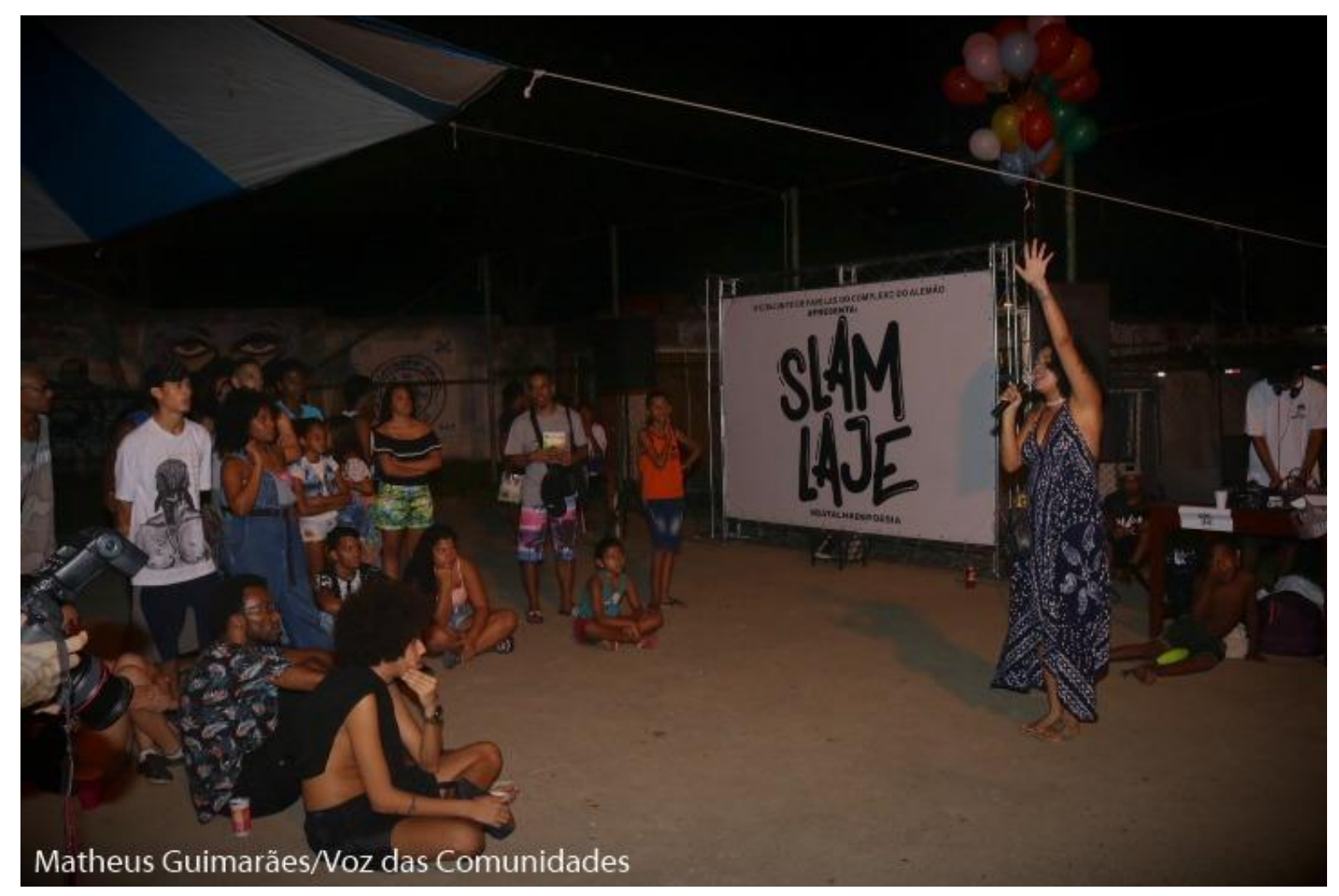

Fonte: Foto de Matheus Guimarães / Voz das Comunidades

\footnotetext{
${ }^{24}$ Costa e Barbosa, 2016.

25 As chamadas redes digitais também se tornam palco de sexismos, xenofobias, racismos, difamações e intolerâncias religiosas, muitas vezes protegidas pelo anonimato, caracterizando os chamados "crimes da internet". As críticas a essas formas e conteúdos de ofensas e injúrias se fazem necessárias, assim como medidas cabíveis da lei e das normativas éticas.
} 
Na Cena de Slam, concurso que envolve a declamação de poesia falada, fazendo de praças, ruas e esquinas suas territorialidades de trocas de repertórios culturais e narrativas estéticas de jovens de favelas, de periferias e de subúrbios, os jovens se fazem visíveis nos seus cantos, em suas poesias e em suas danças, constituindo a reconfiguração da cena pública de seus direitos à cidade. Esses encontros de celebração têm nas mídias virtuais (Facebook, Istagram, WhatsApp) mediações importantes de mobilização e propagação das práticas culturais como virtualidades políticas.

A construção estética dos sujeitos se faz na composição corpo/território como um campo de múltiplas atuações culturais e linguagens artísticas. É um modo geográfico de manifestação de estilos em tensão com padrão consumado e consumível de bens simbólicos impostos ao cotidiano urbano. É nesse sentido que outro desenho de espaço público está em curso na sociedade contemporânea, uma vez que é constituído por diferentes sujeitos em posição de desigualdade de poder que se afirmam em cenas autônomas de apresentação de si. Podemos dizer que estamos diante de uma estética da atitude: emoções, valores e percepções que definem condutas vertidas em linguagens de apropriação sensível do mundo. Falamos então de uma potência da vida dos sujeitos em oposição ao espaço urbano disciplinado pela propriedade privada e controlado pelo consumo mercantil globalizado, portanto demarcadora de sentidos de vida em seus movimentos performáticos de afirmação das existências de jovens, negros e negras em sua maioria, residentes em periferias, subúrbios e favelas ${ }^{26}$.

Nesse sentido, criar territorialidades estéticas a partir de estilos discursivos/ imagéticos/corpóreos é confrontar normativas homogeneizantes que suprimem os múltiplos outros e os definem enquanto perigosos para a vida em comum. Assim, quando sujeitos agem de modo orientado para transformar sua experiência sensível e combater as restrições à diferença, eles também abrem o debate sobre o motivo pelo qual alguns sujeitos são silenciados, invisibilizados e, até mesmo, exterminados ${ }^{27}$.

\section{Considerações Finais}

Quando tratamos dos repertórios do imaginário em uma concepção crítica, particularmente na historicidade de grupos sociais em seus territórios de existência, estamos diante de um duplo desafio: reconhecer e afirmar outros sujeitos sociais na disputa de proposições dos rumos da sociedade, particularmente diante da centralidade da comunicação de massas no contemporâneo. É esta perspectiva que nos leva a incluir os territórios populares nas tramas do devir da cultura urbana sob a hegemonia das mídias industriais.

Observamos que as territorialidades corporificadas contribuem para uma virada do lócus de enunciação do mundo da vida. Trata-se, sobretudo, de recortes geográficos mobilizados por jovens em condição de subalternidade para inventar a visibilidade de si com outros. Nessa perspectiva se inscrevem as pequenas e efêmeras insurreições que transitam entre redes virtuais

\footnotetext{
${ }^{26}$ Deve-se registrar que para além dos coletivos de jovens vinculados a linguagens culturais há a crescente presença de jovens praticantes de religiões de matriz afro-brasileira que mobilizam estratégias de celebrações presenciais associadas a dispositivos digitais.

${ }^{27}$ O homicídio de jovens negros já deve ser considerado como prática de genocídio no Brasil. Dos 56.337 homicídios registrados no país em 2012, 30 mil eram jovens de 15 a 29 anos e 77\% dos jovens mortos eram negros. Índice de Homicídios na Adolescência. IHA 2012. Orgs. Doriam Luis Borges de Melo, Ignacio Cano. Rio de Janeiro: Observatório de Favelas/ SDH/UNICEF/ LAV, 2014. Disponível em <http://prvl.org.br/>.
} 
e territorialidades de ação, provocando fissuras na ordem global verticalizada com suas estéticas de atitude.

Como assegura Canevacci (2009), as representações plurais inovam a comunicação digital justamente porque são compostas por sujeitos que refletem de dentro de suas próprias culturas. Portanto, a inovação da comunicação só se faz possível devido aos sujeitos que criam culturas a partir de seus territórios de existência, uma vez que mobilizam experiências inscritas no cotidiano de construção de seus atos simbólico-existenciais, reunindo o "real" e o "virtual" como narrativa de vivências e percepções que lhes são próprias ${ }^{28}$.

O sentido de "dentro da cultura" deve ser traduzido como corporeidade estética que vibra em encontros presenciais e virtuais de criação e afirmação de pertenças, cujo fundamento é a apropriação e uso do território. É nesta via que os conteúdos de downloads e uploads podem ser tomados como materiais fundamentais para compreender os repertórios manejados pelos jovens, suas vontades de potência na cena pública e sua condição de ser no/do mundo. Configura-se assim um novo universo de pontos de vista, versões de fatos, linguagens poéticas: repertórios de experiências afetivas e existenciais. Agora com outras vozes, cores e forças de diferentes territórios ganham cenas de envolvimento em/com dispositivos de comunicação (Costa e Barbosa, 2016), alcançando milhares de pessoas e, de modo especial, mobilizam diferentes territorialidades culturais para redefinição de usos da cidade, mesmo que sejam efêmeros e fugazes como os bailes, festas e celebrações outras que reúnem juventudes urbanas.

São justamente essas territorialidades de convivências que permitem aos jovens e as jovens superarem as clausuras territoriais impostas pelo constrangimento racial e pela distinção de classe da ordem espacial dominante da cidade.

É com essa linha de argumentação que podemos afirmar que as mídias virtuais assumem a condição contraditória de provocar espetáculos de sensações para o consumo e de serem fissuradas por atos de jovens que exercitam suas inventividades de narração de seus desejos, alegrias e frustações. É a partir destes cenários de conflitos que adentramos ao debate da cultura e das suas relações com sujeitos e territórios, especialmente com os jovens de favelas e periferias urbanas brasileiras. Sujeitos em territorialidades de visibilidade de suas diferenças raciais, étnicas, sexuais, etárias e de gênero - construindo seus modos de apresentação de si com outros. Emergem atos de jovens que se mostram por meio de dispositivos de afirmação virtuais e corpóreos como protagonistas na elaboração de uma agenda renovada de direitos.

Emergem mediações simbólicas expressam modos de apresentação de vivências resultantes do complexo processo pelo qual os significados são produzidos e comunicados entre pessoas de um mesmo grupo cultural para redefinir qualitativamente a temática da política de direitos sociais, sobretudo quando se trata de uma sociedade violenta e desigual como a brasileira.

A comunicação virtual traduz encontros simbólicos entre jovens e, ao mesmo tempo se configuram como dispositivos de mobilidades corpóreas. É nesse sentido que os Bailes Funk e

\footnotetext{
${ }^{28}$ Nos aproximamos aqui da concepção de teia de relações humanas que "desvelam como sujeitos, como pessoas distintas e singulares, mesmo quando inteiramente concentrados na obtenção de um objeto completamente material e mundano", conforme a abordagem original de Hanna Arendt (Arendt, 2010, p. 229).
} 
de Charme, as Rodas de Rima e os Saraus, as Cenas de Slam e o Grafitti ganham a dimensão de modos de visibilidade de direitos de jovens de favelas e periferias nas cidades brasileiras.

O empenho dos jovens é o de saber comunicar com o mundo, mais também com o entorno com outros próximos e outros distantes - buscando criar e alimentar enlaces sociais. Comunicar tem o sentido de pôr em comum, de promover coexistências das diferenças como garantia do exercício de sociabilidade e como prática de liberdade. E, com estes atos, a construção da agenda de polis $^{29}$ como prática de ver e viver a cidade como direito aos direitos.

Portanto, podemos afirmar que circularidade de produtos, práticas e imaginários culturais são indispensáveis para os enriquecimentos sociais e, sobretudo, como um projeto de sociedade democrática. A mobilização de imaginários nas redes digitais conjugadas às apresentações de si em cenas públicas revela uma nova e vigorosa trama política da criação estética, traduzida em seu sentido pleno de compartilhamento e reconhecimento de diferenças para as transformações inadiáveis de nossas cidades.

\section{Referências Bibliográficas}

ARENDT, Hannah. A condição humana. Rio de Janeiro: Forense Universitária, 2010.

BARBOSA, Jorge Luiz; GONÇALVES, Caio. Solos Culturais, 2013. <https://pt.scribd.com/document/207566999/Solos-Culturais>.

BARBOSA, Jorge Luiz. Cultura e Território. Rio de Janeiro: Editora Lumen Juris, 2017.

BENJAMIN, W. A obra de arte na era de sua reprodutibilidade técnica. In BENJAMIN, W. Obras escolhidas: magia e técnica, arte e política. São Paulo: Brasiliense: 1994, $7^{\mathrm{a}}$ ed. p. 165196.

BERCK, Ulrich. Was ist globalissierung? Frankfurt: Suhrkamp, 1988.

CANEVACCI, Massimo. Antropologia da Comunicação Visual. São Paulo. Ed. Brasiliense, 2009.

CASTEL, Michel. A galáxia da internet. Rio de Janeiro: Jorge Zahar, 2003.

COSTA, Eliane; BARBOSA, Jorge. L. Rolezinhos: território e territorialidades. In Ciberculturas. Z Cultural. Programa Avançado de Cultura Contemporânea. Ano XI, nº1, 2016. Disponível em <http://revistazcultural.pacc.ufrj.br/category/publicacoes/ano-xi/>.

\footnotetext{
${ }^{29}$ Trata-se da construção de ações políticas consistentes e articuladas de Direitos à Cidade, cujos vínculos explícitos celebrados na cena pública apontam para a radicalização ética e estética da democracia. Henri Lefebvre, em o Direito à Cidade, oferece uma bela pista de princípios para agenda de polis: "O direito à cidade se manifesta como forma superior dos direitos: direito à liberdade, à individualização na socialização, ao habitat e ao habitar. $\mathrm{O}$ direito à obra (à atividade participante) e o direito à apropriação (bem distinto do direito à propriedade) estão implicados no direito à cidade".
} 
COSTA, Eliane. Jangada Digital. <http://elianecosta.com.br/wpcontent/uploads/2015/10/JANGADA_DIGITAL_Eliane_Costa_pdf_completo.pdf>.

DORIAM, Luís Borges de Melo; CANO, Ignácio. Índice de Homicídios na Adolescência. IHA 2012. Rio de Janeiro: Observatório de Favelas/ SDH/UNICEF/ LAV, 2014. Disponível em $<$ http://prvl.org.br/>.

FEATHERSTONE, Mike; LASH, Scott.; ROBERTSON, Roland. Globall Modernites. Sage: Londres, 1995.

HALL, Stuart. A identidade cultural na pós-modernidade. Rio de Janeiro: DP\&A Editora, 2006, $11^{a}$ ed. Disponível em <https://leiaarqueologia.files.wordpress.com/2018/02/kupdfcom_identidade-cultural-na-pos-modernidade-stuart-hallpdf.pdf >

HERSCHMANN, Micael. O funk e o hip hop invadem a cena. Rio de Janeiro: UFRJ, 2005 Disponível em <https://micaelherschmann.files.wordpress.com/2013/05/o-funk-e-o-hip-hopinvadem-a-cena.pdf $>$.

HARVEY, David. A Produção Capitalista do Espaço. São Paulo: Annablume, 2005.

LEFEBVRE, Henri. O direito à cidade. São Paulo: Centauro, 1991.

LEVY, Pierre. Cibercultura. São Paulo: 1999, ed. 34.

LIPOVETSKY, Gile; SERROY, Jean. A estetização do mundo: viver na era do capitalismo artista. São Paulo: Companhia das Letras, 2015.

RIBEIRO, Ana Clara Torres. Outros territórios, outros mapas. In OSAL. Observatório Social de América Latina. Ano 6, 16 (jun. 2005). Buenos Aires: CLACSO, 2005. I.

SACK, Robert D. The meaning of territoriality. Human Territoriality, is theory and history. Cambridge: Cambridge University Press, 1986.

SANTOS, Milton. Por uma outra globalização. Rio de Janeiro: Record, 2003.

SANTOS. Milton. A natureza do espaço. Ed. USP, $4^{\mathrm{a}}$ edição: 2002.

SANTOS, Milton. O papel ativo da geografia: um manifesto. Florianópolis. In XII Encontro Nacional de Geógrafos, 2002 <https://suburbanodigital.blogspot.com/2015/12/o-papel-ativoda-geografia-um-manifesto-milton-santos.html>.

VENTURA, Tereza. Cultura e representação política. In ALVES, Paulo C. (org.). Cultura: múltiplas leituras. Salvador: Editora EDUFBA, 2010.

(c) Copyright: Jorge Luiz Barbosa, 2020.

(C) Copyright: Ar@cne, 2020. 
Territorialidades em redes digitais de culturas globais...

Ficha bibliográfica:

BARBOSA, Jorge Luiz. Territorialidades em redes digitais de culturas globais: juventudes de favelas e periferias em suas estéticas de atitude. Ar@cne. Revista Electrónica de Recursos de Internet sobre Geografía y Ciencias Sociales. [En línea]. Barcelona: Universidad de Barcelona, $\mathrm{n}^{\circ}$ 239, 1 de febrero de 2020. <http://www.ub.edu/geocrit/aracne/aracne-239.pdf>. ISSN: 1578-0007.

Menú principal de Geo Crítica
Índice de Ar@cne 